\title{
Collapsed roof trusses kill carpenter foreman
}

\section{SUMMARY}

A 33-year old carpenter foreman was killed when the roof truss system he and his crew were installing collapsed. The victim was hired to be the foreman for a project to construct a residential shop building. A few days before the incident the crew began framing, sheeting and bracing the external four walls. On the day of the incident, vertical truss bracing (2 X 4's) were nailed to the north and the south wall (see Figure 2). The truss manufacturer arranged for the delivery of the trusses on a trailer pulled by a truck-mounted crane. The truck operator provided the foreman with the delivery packet containing the BCSI-B1 Sumary SheetGuide to Handling, Installing, Restraining and Bracing of Trusses (see Reference \#7) before setting up to

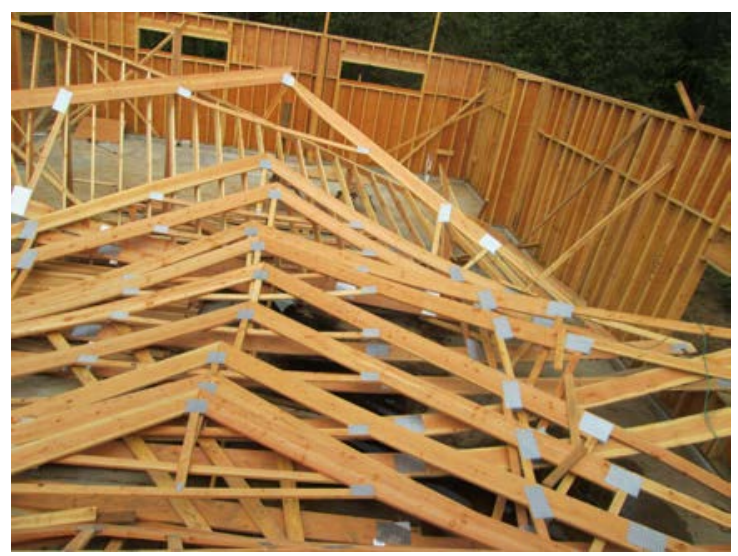

Figure 1. Collapsed trusses where the incident occurred.

offload the trusses from the trailer. The foreman assigned each of his four-man crew their positions and tasks. The foreman worked the center span of the trusses installing bracing and runners and unhooking each truss from the crane rigging. After the thirteenth truss was toenailed into its place and the temporary short member top chord lateral restraint was installed, the victim disconnected the truss from the rigging. The truck operator and crew member on the trailer saw the truss system collapsing and yelled to warn the crew. The two crew members working on the top plates of the framed walls were knocked off the structure to the concrete floor below and were injured from the fall and falling trusses. The worker on the concrete floor beneath the erected trusses cutting lateral restraints to size sustained a head concussion. The victim sustained a fatal head injury when he was struck on the head by a falling truss.

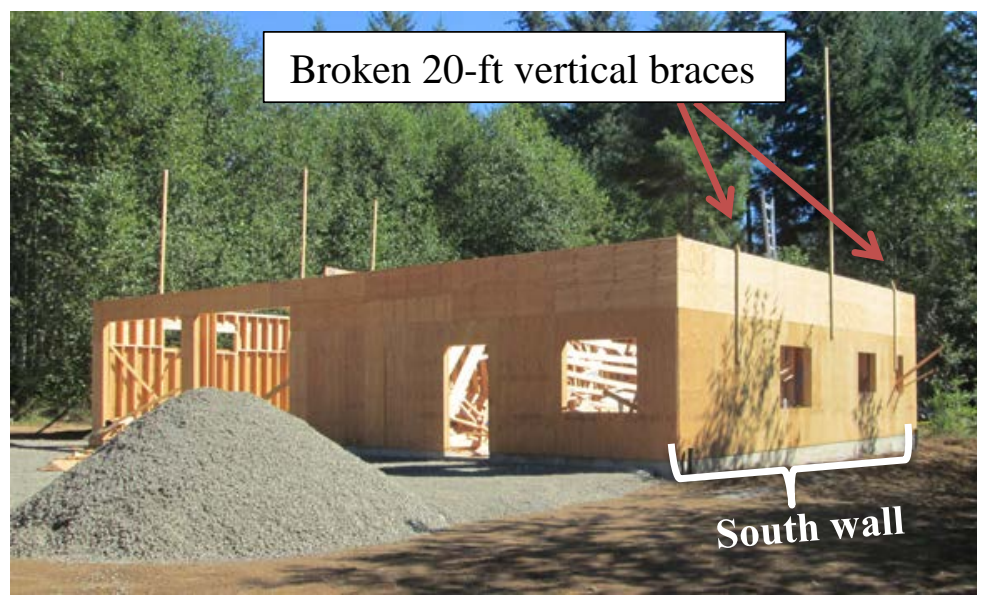

Figure 2. The shop/garage building with collapsed trusses within the structure. Note the 2X4's nailed to the outside of the south wall and that ground bracing was not erected. Middle vertical brace remained unbroken. 


\section{RECOMMENDATIONS}

- Employers and supervisors should assess the workplace hazards and plan each stage of construction to comply with manufacturer's recommendations or standard best practice. In this case, the critical elements of standard practice provided in the BCSI-B1 Summary Sheet for adequate bracing prior to and during truss installation were not followed.

- Employers must train supervisors and employees, communicate their expectation for following safe practices and confirm that employees fully understand the hazards and controls required for the task assigned. In this case, training and expectations were lacking and the truss installation did not include a review of standard documents, pre-job assessment, risk mitigation planning or the use of personal protective equipment.

- Employers should develop and use a hiring process that is based on established best practices, including a process to determine candidates' qualifications and training needs before they begin work on assigned tasks.

OR-FACE supports the prioritization of safety interventions using a hierarchy of safety controls, where top priorities are hazard elimination or substitution, followed by engineering controls, administrative controls (including training and work practices), and personal protective equipment.

\section{INTRODUCTION}

In September 6, 2013, a carpenter foreman was killed when he fell and was struck by a truss as it collapsed during installation. OR-FACE was notified by Oregon OSHA of the incident. ORFACE visited and inspected the undisturbed site with the assigned OR-OSHA investigator.

The employer was a family-owned roofing company that primarily installed residential and commercial roofing but provided additional services such as roof cleaning/maintenance, siding installation, interior and exterior painting, excavation, and framing. At the time of the incident the company employed approximately 15 non-union workers.

The employer was contracted by the property owner to construct a residential shop/garage building. When construction was ready to begin the employer had other projects in progress and did not have a crew available for the job. The employer conducted interviews by telephone to select the new crew and foreman. At the time of the incident the employer had not met any of the crew members. The victim was a carpenter for four years and two of those years as head framer and supervisor. He was recommended by a previous supervisor for the job and based on that recommendation he was hired as the foreman for the job. 
Four days prior to the incident the crew began framing, sheeting and bracing the four 12-foot walls and completed framing the 12-foot interior wall separating shop and garage. On the day of the incident, the crew nailed three 20-foot 2 X 4's vertical braces to the north and south wall before the trusses were delivered. No external ground braces or restraints were installed. The trusses for the 40 ' X 60' building were delivered to the site on a trailer pulled by a crane mounted truck. Each truss was lifted by the crane and set in place on the structure one at a time and installed by a five-person crew. As each truss was added, the crew nailed temporary lateral restraints on the top chords but not diagonal bracing. Evidence suggests that the foreman walked along a center board secured to the bottom chords to access and release each truss from the rigging. After the thirteenth truss was toe nailed into its place, the victim disconnected the truss from the rigging. The crane operator and the crew member on the trailer saw and tried to warn the crew within the structure of the collapsing trusses. Two crew members fell off the top plates of the east and west wall and were treated for neck, head and back injuries. The worker on the concrete floor assigned to cut lateral restraints was struck by the falling trusses and sustained

a head concussion. The victim fell to the concrete floor and was fatally struck by a falling truss.

The employer did not provide training on the hazards of framing and truss installation and the crew was not provided nor required by the employer to wear any protective equipment, such as hard hats, safety glasses, or fall protection.

\section{INVESTIGATION}

OR-OSHA and OR-FACE observations, recorded crew and crane operator interviews, medical examiner report, police report and death certificate were obtained to complete this report.

The site where the incident occurred was on private property where the property owner contracted a construction company to erect a residential shop/garage building. When the property owner was ready to begin framing the building, the employer, a roofing/construction company was busy with other projects and needed additional workers for the job. The company hired a new crew for the job and the victim was hired to be the foreman through the recommendations of another contractor and a telephone interview. Three of the crew members were also interviewed, selected and hired by telephone. The last crew member was hired and brought onsite on the day of the incident by the foreman. None had worked for the company previously nor did any of the crew members ever worked together. The employer planned to meet the crew the week following the incident.

The surviving workers interviewed after the incident revealed that neither training nor protective equipment were provided or required by the employer. Construction experience varied among workers and it was not known whether they had work experience as a crew erecting/installing trusses. Two of the workers began working at the jobsite a few days before the incident where they framed, sheeted and braced the four outer 12-foot high walls.

On the morning of the incident, two workers arrived at the job site for the first time. The crew completed the framing of the interior wall that would separate the garage from the shop. At the south end of the structure the crew nailed three 20-foot long 2X4's to the outside of the south wall (see Figure 2). Contrary to the Structural Building Components Association, BCSI-B1 
Summary Sheet (see Figure 4 and Reference \#7) additional diagonal external or internal ground bracing was not installed along the south wall, the gable end. One worker explained in his recorded interview that the practice he observed on the job was consistent with his experience on similar jobs.

At approximately 12:30 pm, a truck-mounted crane with a trailer loaded with the trusses arrived at the jobsite. The truck operator provided the foreman with the delivery documents containing the Structural Building Components Association (SBCA) BCSI-B1 Summary Sheet-Guide. He then assessed the area to determine the location where he could set-up the crane to offload and set the trusses in place on the structure one at a time. The driver estimated that each truss was approximately 200 pounds. These trusses were believed to be designed for

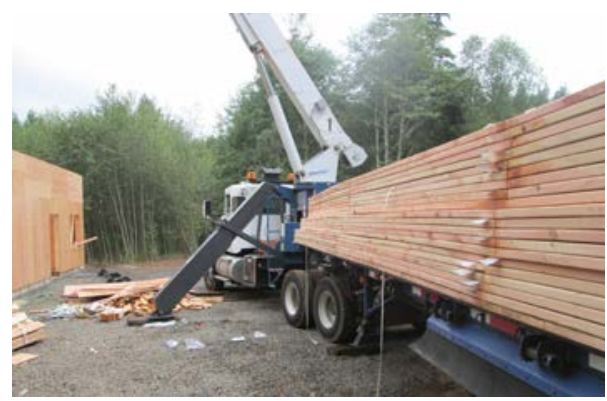

Figure 3. Truck-mounted crane with trusses on the trailer the area snow load of 30 pounds/square feet. Thus, they were heavier than trusses constructed for areas at lower elevation with a minimum design snow load of 25 pounds/square feet.

The foreman assigned one worker to stand on the trailer and connect each truss to the crane rigging. Two others were assigned to stand on top plates of the framed walls, one on the east wall and the other on the west wall to receive and secure the trusses at their end. The fourth worker was assigned to be on the concrete floor to cut lateral restraints to length, 2 feet long or as requested, and hand them to the workers above.

When the gable end truss was set in place, it was toe nailed to the plate then nailed to the three 20 -foot vertical braces within reach on the south wall. The second truss was set in place and nailed to the top plate on the west and east wall. Two 2X4's cut to approximately two feet long were cut and handed to the two workers on the east and west wall who then nailed each end, one to the gable end truss and the other to the second truss at approximately 8 feet from the toe, at the top of the truss stringers. Each additional truss was attached similar to the second truss with 2X4's temporary lateral restraints nailed to the preceding truss and the one that was just set in place. The foreman worked in the center span of the trusses and installed bracing and runners. After each truss was set in place the foreman disconnected the truss from the rigging.

According to the OSHA report and recorded interviews, the crane operator and the worker assisting him, called out to the foreman several times that bracing was inadequate. In response, additional temporary lateral restraint boards were added between the first six east side vertical truss web members and across the first nine west side vertical web truss members but not ground braces or diagonal braces. The process continued until after the $13^{\text {th }}$ truss was set in place. The foreman disconnected the truss from the rigging. As the rigging cleared the truss by approximately one foot, the crane operator and the worker on the trailer saw the trusses falling and tried to warn the crew.

The crew member who was working on the trailer attaching the crane rigging to lift each truss called 911 for emergency assistance. The foreman and two crew members were knocked of their elevated positions to the concrete floor below. The worker positioned on the concrete floor 
cutting the lateral restraints to size was struck on his head, suffered a concussion and was transported by helicopter to a hospital. The two workers who fell off the top plate of the walls were taken by ambulance to different hospitals. In a recorded interview one of these workers indicated bruises and injury to his neck, head and back. The other reported that he injured his back in the fall. The victim was struck on his head by a falling truss sustaining a fatal head injury.

\section{CAUSE OF DEATH: Blunt force head trauma.}

\section{RECOMMENDATIONSIDISCUSSION}

Recommendation \# 1: Employers and supervisors should assess the workplace hazards and plan each stage of construction to comply with manufacturer's recommendations or standard best practice. In this case, the critical elements of standard practice provided in the BCSI-B1 Summary Sheet for adequate bracing prior to and during truss installation were not followed.

- The truss manufacturer document, Structural Building BCSI-B1 Summary Sheet (see Reference \#7 and Figure 4 below for recommended bracing) provided upon delivery, warned of potential collapse if improperly handled, erected, installed, restrained or braced. Evidence from pictures taken immediately after the incident and from recorded interviews and discussion with the OSHA inspector confirmed that adequate bracing was not installed and a bracing plan was not discussed with the crew. Three vertical 2X4's nailed to the outside of the south wall were used to brace the first gable truss but without ground bracing, struts or restraint (see Figure 5 to view bracing installed on day of incident). The guide specifically states that step 1 for setting trusses is to, "install ground bracing." Additionally, it recommended diagonal bracing at each end and for each set of four trusses. The BCSI booklet 2013 edition (see Reference \#6) provides best practices and includes a checklist for the erection/installation process and safety reminders. Among the BCSI recommendations

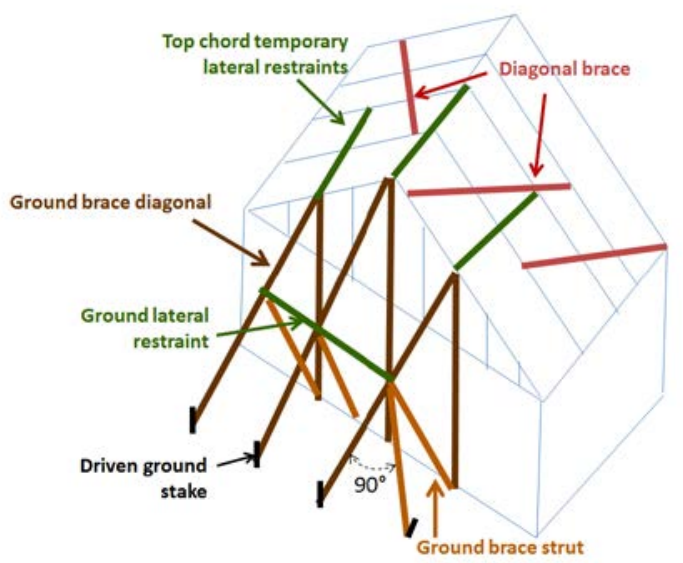

Figure 4. Recommended bracing schematic 1. Adapted from diagrams in BCSI-B1 Summary Sheet-Guide to Handling, installing, Restraining and Bracing of Trusses (see Reference \#7 for complete information).

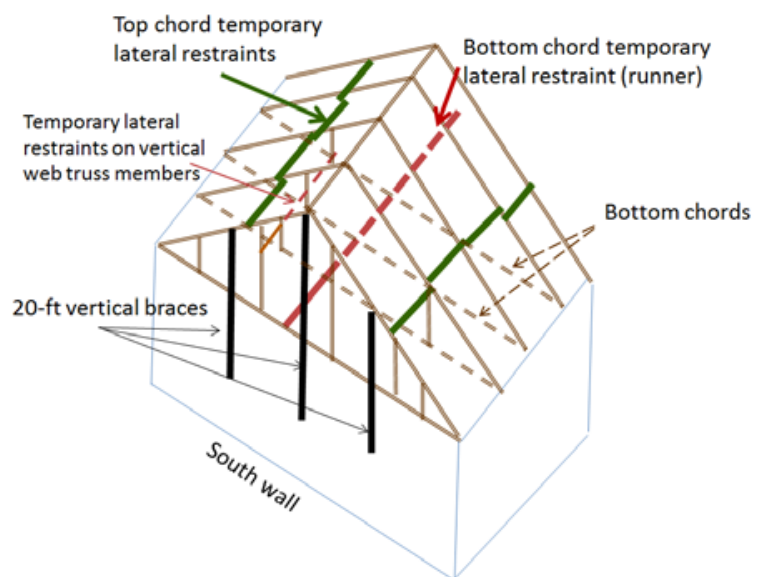

Figure 5. Implemented bracing schematic 2. This schematic represents the braces and restraints believed to have been installed by the crew on the day of the incident. 
was, "brief all members of the erection/installation crew as to the installation plan and the intended lateral restraint and diagonal bracing requirements.” A specific notice (see page 19) warns that, "the use of ground brace verticals alone, attached to the end wall, is not considered good construction practice and is not permitted."

- In addition to best practices for adequate bracing recommended by the BCSI, alternate methods of truss installation that may be used to reduce or eliminate hazards are presented in OR-OSHA's document, "Fall Protection: Safe Practices for Setting and Bracing Wood Trusses and Rafters" (see Reference \#2). The document contains alternative methods to eliminate or minimize fall hazards while working on elevated surface. Examples from this document are shown in the pictures below. These pictures show an alternative method of erecting and sheeting a series of trusses on the ground and then lifting the unit into place with a crane. The added use of externally mounted scaffolding further reduces fall hazards. The OSHA fatality and catastrophic database was analyzed for incidents during the years 19902009 pertaining to trusses (see Reference \#9). The study data showed that falls are a major hazard in setting of trusses.

- Wood trusses are not designed to support a fall-arrest system and should not be used to tieoff personal fall protection devices. The height of the walls was 12 feet, thus workers were above the height required by OR-OSHA for fall protection (see Reference \#5). To minimize fall hazards, installing internal and/or external scaffolds are options that could have been considered. Figure 2, a photograph of the structure, does not show evidence of scaffolding or other fall protection methods. In recorded interviews employees expressed that they were not trained on fall hazards.

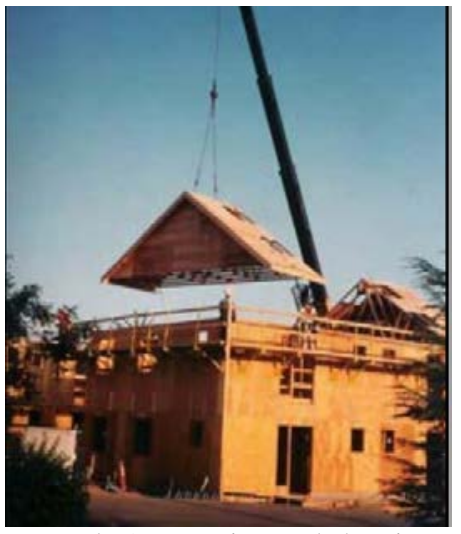

Example 1. Erecting and sheeting a series of trusses on the ground and then lifting the unit into place with a crane.

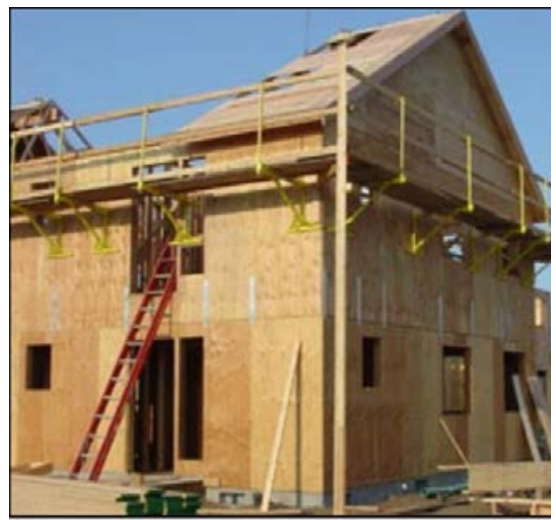

Example 2. Exterior scaffolding on structure.

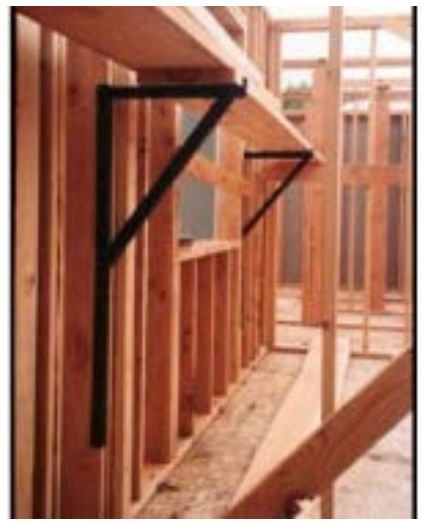

Example 3. Interior scaffolding.

Figure 6. Three construction methods to minimize fall hazards when erecting trusses.

Recommendation \#2: Employers must train supervisors and employees, communicate their expectation for following safe practices and confirm that employees fully understand the hazards and controls required for the task assigned. In this case, training and expectations were lacking and the truss installation did not include a review of standard documents, pre-job assessment, risk mitigation planning or the use of personal protective equipment. 
- OR-OSHA investigation documents, OR-FACE observations and a review of recorded interviews revealed that workers neither knew nor were trained on the hazards and safe practices for the work assigned. Workers expressed that they were not provided new employee orientation and that the employer planned to meet the crew and deliver employment paperwork the week following the incident. New employee orientation is an opportunity to familiarize employees with the company's basic practices and expectations. It is also an opportunity for employees to raise concerns, and the employer to ensure employees have appropriate personal protective equipment and tools for the job.

- Observing or mentoring new workers by an experienced company employee while new workers conduct their tasks is an accepted practice to verify required skills and understanding of employer's expectations. This would be especially critical in high risk environments. In this incident, it was the first day on the job for two workers. All members of the crew were newly hired for the job. Three workers stood on the top plate of a 12 foot wall operating a nail gun. None of the crew wore typical construction PPE for falling and/or flying hazards (eye, head, or foot protection) nor did they articulate that they knew fall hazards or other hazards associated with erecting trusses.

\section{Recommendation \# 3: Employers should develop and use a hiring process that is based on established best practices, including a process to determine candidates' qualifications and training needs before they begin work on assigned tasks.}

- The employer hired the victim and crew through job interviews over the telephone. Whether the employer evaluated each candidate's qualifications based on the job requirements is not clear. The surviving crew members reported not being aware of a bracing plan, best practices or hazards related to the task. The victim was believed to have been an experienced framer/carpenter, however, it was not known whether he had experience erecting trusses and or understood the importance of following manufacturer requirements and standard practices. The Building Component Safety Information (BCSI) B1 Summary SheetGuide for Handling, Installing, Restraining and Bracing Trusses (see Reference \#7) was provided to the foreman upon delivery of the trusses. However, evidence suggests that the crucial elements of the Guide were not implemented. There were no external or internal ground braces installed before erecting the gable end truss and even after repeated comments by the crane operator, diagonal bracing was not applied for stabilization.

- The questions asked during the job interview are not known. Recorded interviews with the investigator after the incident suggest that the employer relied heavily on verbal recommendations, limited face-to-face interaction, and conducted no inquiries about skills and knowledge of standard practices for installing trusses. Suggested interview questions to enable the employer to determine the candidate's technical knowledge and whether the person is a good fit for the organization are provided in Professional Safety, "Interviewing for Safety: Asking the right questions,” (see Reference \#1). The article author defines highvalue questions as, "questions that allow the candidate to offer specific details that help paint a picture of the candidate's qualifications and fit" A sample question in the article, "What safety training have you received? If you were hired, what safety issues would you expect to be trained on?" may have elicited an answer indicating the extent of the candidate's inexperience and what training would be required. The additional question, "what documents would you review and discuss with employees before starting the job?” may have 
revealed that the foreman was not aware of the SBCA guide which was critical in determining adequate bracing for the job.

\section{REFERENCES}

1. LaBelle, Jeffrey, MS, MBA, CSP, CIH. Nov 2010 Professional Safety. Interviewing for Safety: Asking the right questions.

2. Oregon OSHA. Fall Protection: Safe Practices for Setting and Bracing Wood Trusses and Rafters. Available online: http://www.orosha.org/pdf/pubs/2824ae.pdf

3. Oregon OSHA 2010. The ABCs of Construction Site Safety. Available online: http://www.orosha.org/pdf/pubs/4878.pdf

4. Oregon OSHA 2010. Fall Protection for the Construction Industry. Available online: http://www.cbs.state.or.us/external/osha/pdf/pubs/2824.pdf

5. Oregon OSHA, Oregon Administrative Rules, Subdivision M, Fall Protection. Available online: http://www.cbs.state.or.us/osha/pdf/rules/division_3/div3m.pdf

6. Structural Building Components Association (SBCA) 2013. Building Component Safety Information: Guide to Good Practice for Handling, Installing, Restraining \& Bracing of Metal Plate Connected Wood Trusses. Copyrighted pdf available online: http://support.sbcindustry.com/docs/06_BCSI_booklet_FINAL.pdf

7. Structural Building Components Association (SBCA). BCSI-B1 Summary Sheet-Guide to Handling, Installing, Restraining and Bracing of Trusses. Copyrighted pdf available online: http://support.sbcindustry.com/images/publication_images/b1.pdf?PHPSESSID=98rvehh1j3 $\underline{\text { tae9c3v8asvnndu1 }}$

8. WorkCover NSW Erection of timber roof trusses. Available online: http://www.workcover.nsw.gov.au/formspublications/publications/Documents/erectiontimber-roof-trusses-1410.pdf

9. Grant, Aneurin and Jimmie Hinze, January 2014. Safety Science, Vol 65, Pages 54-62. Construction worker fatalities related to trusses: An analysis of the OSHA fatality and catastrophic incident database. Available online:

http://www.sciencedirect.com/science/article/pii/S0925753513003226 


\section{FOR MORE INFORMATION}

OR-FACE/Oregon Institute of Occupational Health Sciences L606

Oregon Health \& Science University

3181 SW Sam Jackson Park Rd

Portland OR 97239-3098

Phone 503-494-2281

Email: orface@ohsu.edu

Website: http://www.ohsu.edu/xd/research/centers-institutes/oregon-institute-occupational-health-

sciences/outreach/or-face

Oregon Fatality Assessment and Control Evaluation (OR-FACE) is a project of Oregon Institute of Occupational Health Sciences at Oregon Health \& Science University (OHSU). OR-FACE is supported by a cooperative agreement with the National Institute for Occupational Safety and Health (NIOSH) (grant \#2U60OH008472-06) through the Occupational Public Health Program (OPHP) of the Public Health Division of the Oregon Health Authority.

OR-FACE reports are for information, research, or occupational injury control only. Safety and health practices may have changed since the investigation was conducted and the report was completed. Persons needing regulatory compliance information should consult the appropriate regulatory agency.

The following report is the product of our Cooperative State partner and is presented here in its original unedited form from the state. The findings and conclusions in each report are those of the individual Cooperative State partner and do not necessarily reflect the views or policy of the National Institute for Occupational Safety and Health. 